\title{
HUBUNGAN TEKNIK HIPNOTERAPI TERHADAP PENURUNAN TINGKAT NYERI HAID PADA REMAJA PUTRI DI SMK PELITA AL- IKHSAN KECAMATAN UJUNG JAYA KABUPATEN SUMEDANG TAHUN 2015
}

\section{OLEH :}

\author{
Yanti Susan $^{1}$, Yuli Yuliani ${ }^{2}$
}

\section{A. ABSTRAK}

Dismenorea dapat dialami lebih dari setengah wanita yang sedang menstruasi, dan prevalensinya sangat bervariasi. Salah satu teknik non farmakologis untuk mengurangi rasa nyeri adalah dengan teknik hipnoterapi. Penelitian ini bertujuan untuk mengetahui hubungan teknik hipnoterapi terhadap penurunan tingkat nyeri haid pada remaja putri di SMK Pelita Al-Ikhsan Kecamatan ujungjaya Kabupaten Sumedang Tahun 2015. Tujuan dilakukan penelitian ini adalah untuk mengetahui apakah ada hubungan teknik hipnoterapi terhadap penurunan tingkat nyeri haid pada remaja putri di SMK Pelita Al-Ikhsan Kecamatan ujungjaya Kabupaten Sumedang Tahun 2015.

Jenis penelitian yang digunakan yaitu penelitian kuantitatif dengan pendekatan cross sectional. Sampel dalam penelitian ini menggunakan Total sampling yaitu seluruh remaja putri di SMK Pelita Al-Ikhsan Kecamatan Ujung Jaya Kabupaten Sumedang Tahun 2015 dengan jumlah 119 orang.

Hasil penelitian menunjukkan bahwa sebagian besar remaja putri menyatakan nyeri sedang pada saat mengalami haid dan setelah dilaksanakan hipnoterapi sebagian besar nyeri berkurang dengan skala nyeri ringan. Terdapat hubungan teknik hipnoterapi terhadap penurunan tingkat nyeri haid pada remaja putri di SMK Pelita Al-Ikhsan Kecamatan Ujung Jaya Kabupaten Sumedang dengan nilai $p=$ 0,003 atau $<\alpha=0,05$.

Saran pada penelitian ini yaitu agar remaja putri dapat melakukan hipnoterapi secara mandiri untuk mengatasi nyeri pada saat haid sehingga tidak mengganggu aktivitas belajar.

\section{Kata Kunci: Hipnoterapi, Nyeri Haid, Remaja Putri}




\section{B. Latar Belakang}

Dismenorea dapat dialami lebih dari setengah wanita yang sedang menstruasi, dan prevalensinya sangat bervariasi. Berdasarkan data dari berbagai negara, angka kejadian dismenorea di dunia cukup tinggi. Diperkirakan $50 \%$ dari seluruh wanita di dunia menderita dismenorea dalam sebuah siklus menstruasi. Pasien melaporkan nyeri saat haid, dimana sebanyak $12 \%$ nyeri haid sudah parah, 37\% nyeri haid sedang, dan $49 \%$ nyeri haid masih ringan (Kamila,2011).

Di Indonesia angka kejadian dismenore primer sebesar $54,89 \%$ sedangkan sisanya adalah penderita tipe sekunder. Dismenore menyebabkan $14 \%$ dari pasien remaja sering tidak hadir di sekolah dan tidak menjalani kegiatan sehari-hari (Kamila,2011).

Proses haid merupakan masalah yang kompleks. Proses ini tidak hanya dilandasi oleh perubahan endometrium serta

stroma uterus, tetapi juga melibatkan fungsi-fungsi jaringan lainnya, yang melibatkan interaksi hormon-hormon. interaksi tersebut serta dampaknya pada jaringan

reproduksi dipengaruhi oleh rangsangan hipotalamus serta adanya mekanisme umpan balik, pada proses haid yang umum yaitu 28 hari dalam satu daur (Handono, 2010)

Dismenore merupakan

nyeri pada abdomen yang dirasakan sesaat sebelum atau pada saat menstruasi dan mengganggu aktivitas perempuan, bahkan sering kali mengharuskan penderita beristirahat dan meninggalkan pekerjaannya selama berjam-jam akibat dismenore (Kamila,2011).

Berdasarkan penelitian yang pernah dilakukan oleh Meliani Dina di SMAN Situraja Kabupaten Sumedang terdapat 10 siswi yang mengalami menstruasi, didapatkan 6 orang $(60 \%)$ menyatakan sering sakit pada bagian perut bawah dan 4 orang (40\%) menyatakan tidak terlalu sakit pada bagian perut bawah karena sakitnya masih bisa di atasi, hasil penelitian menunjukkan sebagian besar responden mengalami dismenore dengan tingkat nyeri tidak terkontrol (Meli, 2014)

Sedangkan hasil penelitian yang dilakukan oleh Lisnawati Mela menyatakan bahwa sebagian besar siswi di SMAN 3 Sumedang mengalami nyeri haid ringan dan sebagian mengalami nyeri haid sedang (Lisnawati, 2013).

Cara mengurangi

dismenore dapat dilakukan dengan 2 cara yaitu farmakologi dan non farmakologi. secara non farmakologi dapat dilakukan kompres hangat, massase, latihan fisik, tidur yang cukup, hipnoterapi, distraksi seperti mendengarkan musik serta relaksasi seperti yoga dan nafas dalam (Siahaan, 2013).

Berdasarkan dari 2 penelitian yang pernah dilakukan, dapat disimpulkan bahwa kasus dismenore pada remaja putri di

beberapa SMA dan SMK Kabupaten Sumedang masih sering terjadi. Peneliti tersebut melakukan penelitian mengenai tingkat nyeri haid tetapi peneliti disini tertarik untuk melakukan penelitian 
mengenai cara penanganan tingkat nyeri haid tersebut dengan menggunakan teknik relaksasi selfhypnosis.

Kunci dari hypnosis adalah adanya kekuatan sugesti atau keyakinan terhadap sesuatu hal yang positif yang muncul berdasarkan pada konsep dalam pikiran, sehingga akan memberikan energi positif bagi suatu tindakan yang dilakukan (Astara,2010).

Berdasarkan data sementara yang peneliti peroleh pada saat studi pendahuluan di SMK dan SMA di Kabupaten Sumedang, diantaranya : SMAN 1 Cimalaka, SMAN 1 Tomo, SMK WIN Sumedang dan SMK Pelita AlIkhsan di dapatkan hasil bahwa di SMAN 1 Cimalaka Pada kasus nyeri haid ringan dan sedang $(70 \%)$ remaja putri masih bisa mengikuti pelajaran sekolah seperti biasa tetapi rasa nyeri haid dapat mengganggu konsentrasi belajar, sedangkan pada kasus nyeri haid berat terkontrol $(20 \%)$ remaja putri berada di UKS dan tidak bisa mengikuti pelajaran sekolah seperti biasa, di SMAN 1 Tomo di dapatkan hasil bahwa (60\%) remaja putri masih bisa mengikuti pelajaran sekolah seperti biasa tetapi rasa nyeri haid dapat mengganggu konsentrasi belajar, $(13,3 \%)$ remaja putri berada di UKS dan tidak bisa mengikuti pelajaran sekolah seperti biasa, di SMK Pelita Al-Ikhsan di dapatkan hasil bahwa $(73,3 \%)$ remaja putri masih bisa mengikuti pelajaran sekolah seperti biasa tetapi rasa nyeri haid dapat mengganggu konsentrasi belajar, $(26,7 \%)$ remaja putri berada di UKS dan tidak bisa mengikuti pelajaran sekolah seperti biasa, $(13,3 \%)$ remaja putri pulang dan tidak bisa mengikuti pelajaran sekolah seperti biasa, di SMK WIN
Sumedang di dapatkan hasil bahwa $(50 \%)$ remaja putri masih bisa mengikuti pelajaran sekolah seperti biasa tetapi rasa nyeri haid dapat mengganggu konsentrasi belajar, $(15 \%)$ remaja putri berada di UKS dan tidak bisa mengikuti pelajaran sekolah seperti biasa.

Berdasarkan data diatas setelah dilakukan preetest dengan menggunakan lembar Numerical Rating Scale (NRS) pada hari selasa tanggal 29 September 2015 bahwa angka tertinggi terjadinya kasus dismenore berada di SMK Pelita A-Iksan sejumlah 15 remaja putri di SMK Pelita Al-Ikhsan menderita nyeri haid, diantaranya nyeri haid ringan sejumlah 2 orang $(13,3 \%)$, nyeri haid sedang sejumlah 9 orang $(60 \%)$, nyeri haid berat terkontrol sejumlah 4 orang $(26,7 \%)$,Nyeri haid berat tidak terkontrol sejumlah 1 orang

(6,7\%). Sehubungan dengan adanya permasalahan tentang nyeri haid diatas, maka peneliti tertarik untuk meneliti mengenai Hubungan Teknik Hipnoterapi Terhadap Penurunan Tingkat Nyeri Haid Pada Remaja Putri di SMK Pelita Al-Ikhsan Kecamatan ujungjaya Kabupaten Sumedang Tahun 2015

\section{Metode}

Jenis penelitian ini adalah penelitian kuantitatif, desain penelitian menggunakan cross sectional. Tempat penelitian di lakukan di SMK Pelita Al-Ikhsan Kecamatan Ujung Jaya Kabupaten Sumedang. Penelitian ini dilaksanakan bulan September -

Nopember 2015.Populasi dan Sample dalam penelitian ini adalah seluruh remaja putri di SMK Pelita Al-Ikhsan Kecamatan Ujung Jaya Kabupaten Sumedang Tahun 2015 
dengan jumlah 119 orang. Cara pengambilan sampel dalam penelitian ini menggunakan teknik total sampling. Lembar Numerical Rating Scale (NRS) untuk mengumpulkan data primer dan mengetahui tingkat nyeri :

a. tidak nyeri $=0$

b. nyeri ringan $=1-3$

c. nyeri sedang $=4-6$

d. nyeri berat terkontrol $=7-9$

e. nyeri berat tidak terkontrol $=10$

Daftar tilik, untuk mengumpulkan dan memvalidasi data sekunder tentang : pelaksanaan hipnoterapi. Data yang diperoleh kemudian dianalisis secara manual dan menggunakan program komputerisasi. Analisa yang dilakukan oleh penulis yaitu Analisis Univariat dan Analisis Bivariat dengan menggunakan uji kai kuadrat (chi square).

\section{Hasil penelitian}

Tabel 1. Tingkat Nyeri Haid Berdasarkan Karakteristik Responden di SMK Pelita Al-Ikhsan Kecamatan Ujung Jaya Kabupaten Sumedang

\begin{tabular}{|c|c|c|c|c|}
\hline \multirow[t]{3}{*}{ Tingkat Nyeri } & \multicolumn{4}{|c|}{ Karakteristik Responden } \\
\hline & Usia $<17$ tahun & Menarche & Lama & Tidak \\
\hline & & dini & haid & berolahraga \\
\hline Nyeri berat tidak terkontrol & 10 & 10 & 8 & 8 \\
\hline Nyeri berat terkontrol & 18 & 25 & 15 & 19 \\
\hline Nyeri sedang & 23 & 24 & 41 & 26 \\
\hline Nyeri ringan & 17 & 14 & 38 & 16 \\
\hline Tidak nyeri & 6 & 8 & 11 & 8 \\
\hline
\end{tabular}

Berdasarkan grafik 1 diketahui bahwa sebagian besar responden yang memiliki usia $<$ 17 tahun memiliki tingkat nyeri sedang. Berdasarkan menarche dini diketahui bahwa sebagian besar responden memiliki tingkat nyeri berat terkontrol. Berdasarkan lama haid diketahui sebagian besar responden memiliki tingkat nyeri ringan. Dan berdasarkan responden yang tidak berolahraga sebagian besar memiliki tingkat nyeri sedang.

Tabel 2.Tingkat Nyeri Haid Sebelum Melakukan Teknik Hipnoterapi pada Remaja Putri di SMK Pelita Al-Ikhsan Kecamatan Ujung Jaya Kabupaten Sumedang

\begin{tabular}{|l|l|l|}
\hline \multicolumn{1}{|c|}{ Tingkat Nyeri } & Frekuensi & Presentasi \\
\hline Nyeri Berat tidak terkontrol & 11 & $9,2 \%$ \\
\hline Nyeri berat terkontrol & 26 & $21,8 \%$ \\
\hline Nyeri sedang & 42 & $35,3 \%$ \\
\hline Nyeri ringan & 29 & $24,2 \%$ \\
\hline Tidak nyeri & 11 & $9,2 \%$ \\
\hline
\end{tabular}


Berdasarkan tabel 2 diatas, diketahui bahwa sebagian besar responden menyatakan nyeri sedang pada saat mengalami haid $(35,3 \%)$.

Tabel 3. Tingkat Nyeri Haid Sesudah Melakukan Teknik Hipnoterapi pada Remaja Putri di SMK Pelita Al-Ikhsan Kecamatan Ujung Jaya Kabupaten Sumedang

\begin{tabular}{|l|l|l|}
\hline \multicolumn{1}{|c|}{ Tingkat Nyeri } & Frekuensi & Presentasi \\
\hline Nyeri Berat tidak terkontrol & 5 & $4,2 \%$ \\
\hline Nyeri berat terkontrol & 9 & $7,6 \%$ \\
\hline Nyeri sedang & 29 & $24,4 \%$ \\
\hline Nyeri ringan & 47 & $39,5 \%$ \\
\hline Tidak nyeri & 29 & $24,4 \%$ \\
\hline
\end{tabular}

Berdasarkan table 3 diatas, diketahui bahwa sebagian besar responden menyatakan nyeri ringan pada saat mengalami haid $(39,5 \%)$.

Tabel 4. Hasil UjiChi Square Hubungan Teknik Hipnoterapi terhadap Penurunan Tingkat Nyeri Haidpada Remaja Putridi SMK Pelita Al-Ikhsan Kecamatan Ujung Jaya Kabupaten Sumedang

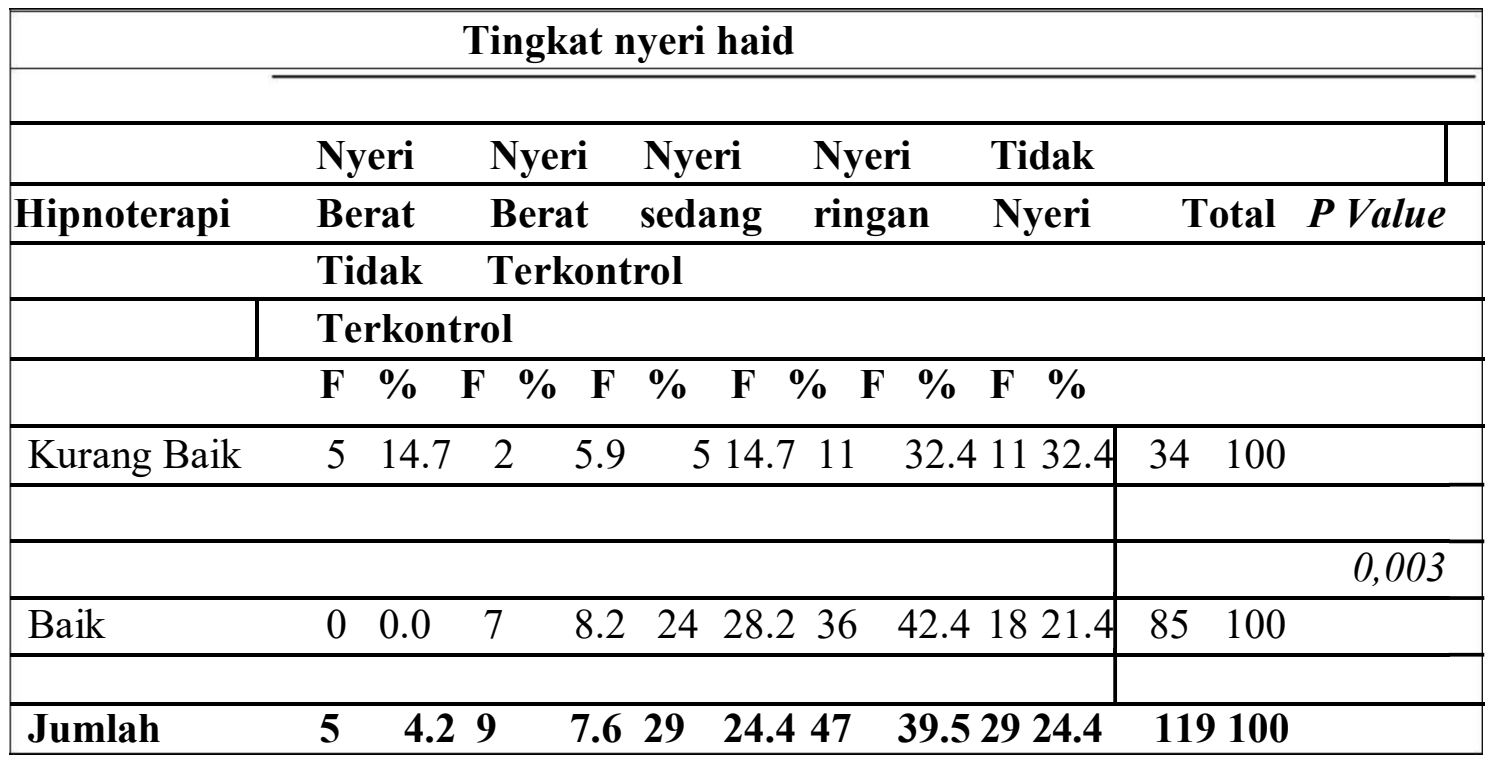

Berdasarkan table 4 menunjukkan bahwa proporsi responden yang mengalami nyeri berat tidak terkontrol pada kelompok yang melaksanakan hipnoterapi kurang baik sebesar $14,7 \%$, sementara proporsi responden yang mengalami nyeri berat tidak terkontrol pada kelompok yang melaksanakan hipnoterapi dengan baiksebesar0\%. Perbedaan ini menunjukkan hubungan yang bermakna yang terbukti dari hasil uji chi square diperoleh nilai $\mathrm{p}=0,003$ atau $<\alpha=0,05$, dengan demikian dapat dikatakan secara statistic yaitu terdapat hubungan teknik hipnoterapi terhadap penurunan tingkat nyeri haid pada remaja putridi SMK Pelita Al-Ikhsan Kecamatan Ujung Jaya Kabupaten Sumedang. 


\section{E. Pembahasan}

Berdasarkan hasil penelitian menunjukkan bahwa sebagian besar remaja putri di SMK Pelita Al-Ikhsan Kecamatan Ujung Jaya Kabupaten Sumedang menyatakan nyeri sedang pada saat mengalami haid $(35,3 \%)$.

Menurut peneliti, usia responden dalam penelitian ini termasuk dalam kategori remaja pertengahan berada pada rentang usia 15-17 tahun. Adanya pengklasifikasian umur responden yang menyatakan bahwa usia remaja dimulai dari usia 10 tahun sampai 19 tahun (WHO,2015), sedangkan menurut peneliti lain menyatakan bahwa usia remaja dimulai dari usia 11 tahun sampai 20tahun (Potter,2010).

Berdasarkan penelitian yang dilakukan bahwa yang paling mempengaruhi tingkat nyeri dismenore terjadi pada usia $<17$ tahun, diantaranya

: nyeri berat tidak terkontrol presentase terbanyak terjadi pada usia $<17$ tahun sebanyak 10 orang $(8,4 \%)$. Sesuai dengan teori bahwa usia dapat mempengaruhi tingkat nyeri dismenore, pada umumnya terjadi pada usia 15-17 tahun, selain itu pada usia tersebut terjadi perkembangan organ-organ reproduksi dan perubahan hormonal yang signifikan (Anekdot, 2014).

Berdasarkan penelitian yang

dilakukan bahwa yang paling mempengaruhi tingkat nyeri dismenore terjadi pada lamanya menstruasi $>7$ hari diantaranya : mengalami nyeri berat tidak terkontrol presentase terbanyak terjadi pada lama menstruasi sebanyak 8 orang $(6,7 \%)$. Sesuai

dengan teori bahwa lamanya menstruasi $>7$ hari dapat mempengaruhi tingkat nyeri dismenore sehingga menimbulkan adanya kontraksi uterus, terjadi lebih lama mengakibatkan uterus lebih sering berkontraksi, dan semakin banyak prostaglandin yang di keluarkan. Produksi prostaglandin yang berlebihan menimbulkan rasa nyeri, sedangkan kontraksi uterus yang terus menerus menyebabkan suplai darah ke uterus terhenti dan terjadi dismenore (Anekdot, 2014).

Berdasarkan penelitian yang dilakukan bahwa yang paling mempengaruhi tingkat nyeri dismenore terjadi pada usia menarche $<12$ tahun diantaranya : yang mengalami nyeri berat tidak terkontrol presentase terbanyak terjadi pada usia menarche dini sebanyak 10 orang $(8,4 \%)$. Sesuai dengan teori bahwa usia menarche yang terlalu dini dapat mempengaruhi tingkat nyeri dismenore dimana organ - organ reproduksi belum berkembang secara maksimal dan masih terjadi penyempitan pada leher rahim, maka akan timbul rasa sakit pada saat menstruasi, karena organ reproduksi wanita belum berfungsi secara maksimal (Anekdot, 2014).

Berdasarkan penelitian yang dilakukan bahwa yang paling mempengaruhi tingkat nyeri dismenore terjadi pada responden yang tidak

mengikuti kegiatan olahraga, diantaranya : yang mengalami nyeri berat tidak terkontrol presentase terbanyak terjadi pada responden yang tidak mengikuti kegiatan olahraga sebanyak orang $(6,7 \%)$. Sesuai dengan teori bahwa kurangnya aktifitas fisik (olahraga) dapat mempengaruhi tingkat nyeri dismenore, kejadian dismenore akan meningkat dengan kurangnya aktifitas selama menstruasi dan kurangnya olahraga, hal ini dapat menyebabkan sirkulasi darah dan oksigen berkurang dan menyebabkan nyeri (Anekdot, 2014). 
Dengan demikian maka asumsi peneliti bahwa nyeri yang dialami oleh responden yaitu nyeri sedang merupakan sesuatu yang fisiologis atau normal, namun meskipun sesuatu yang normal bukan berarti boleh dibiarkan karena nyeri haid yang tidak

mendapatkan penanganan akan berdampak lebih buruk bagi kesehatan siswi dan bahkan dapat mengganggu aktivitas belajar di sekolah. Hal ini sejalan dengan yang dikemukakan oleh teori yang menyatakan bahwa nyeri haid dengan intensitas nyeri sedang memerlukan obat-obatan untuk menghilangkan nyeri tersebut tetapi tidak perlu meninggalkan pekerjaannya sedangkan nyeri haid dengan intensitas nyeri beratmemerlukan obat-obatan, istirahat dandapat mengganggu aktifitas sehari-hari (Manuaba, 2009)

Hasil penelitian menunjukkan bahwa sebagian besar tingkat nyeri remaja putri di SMK Pelita Al-Ikhsan Kecamatan Ujung Jaya Kabupaten

Sumedang setalah melaksanakan hipnoterapi menyatakan nyeri ringan $(42,4 \%)$.

Adanya penurunan atau perubahan tingkat nyeri hal ini berarti bahwa perlakukan hipnoterapi yang dilaksanakan dengan baik akan mampu mengatasi nyeri pada saat haid. Hipnoterapi adalah penggunaan teknik hipnotis secara medis, atau penggunaan teknik relaksasi dalam, yang terutama ditunjukkan untuk mengobati masalah yang timbul akibat faktor psikologis, seperti mengurangi rasa nyeri atau mengubah perilaku. Misalnya, perilaku ketergantungan obat, ketergantungan merokok, penurunan berat badan dan enuresis. Praktisi menggunakan keterampilan konseling yang canggih yang dapat menimbulkan keadaan hipnotik pada klien atau dapat mengajarkan kepada mereka cara menimbulkan hipnosis (Andrew, 2009).

Melihat adanya manfaat hipnoterapi bagi penurunan nyeri haid maka setiap remaja perlu mengetahui hipnoterapi ini sebagai salah satu alternative atau cara yang dapat ditempuh oleh remaja untuk mengatasi nyeri pada saat haid. Jika remaja tidak mengetahui caranya dapat berkunjung kepada petugas kesehatan untuk menanyakan atau sebaliknya petugas kesehatan melakukan penyuluhan

kesekolah-sekolah mengenai hipnoterapi ini.

Berdasarkan hasil penelitian menunjukkan bahwa terdapat hubungan teknik hipnoterapi terhadap penurunan tingkat nyeri haid pada remaja putridi SMK Pelita Al-Ikhsan Kecamatan Ujung Jaya Kabupaten Sumedang. Hal ini terbukti dari adanya perubahan tingkat nyeri pada siswi yang melaksanakan hipnoterapi disbanding pada siswi yang tidak melaksanakan hipnoterapi.

Berdasarkan hasil uji hipotesis tersebutdapat disimpulkan bahwa terdapat hasilyang signifikan dan bermakna dalam penurunan intensitas nyeri yang dialami responden. Adanya perbedaan nilai significancy dapat disimpulkan bahwa Ho ditolak dan $\mathrm{Ha}$ diterima, yang berarti ada hubungan teknik hipnoterapi terhadap penurunan tingkat nyeri haid. Siswi yang menyatakan tidak nyeri pada kelompok yang tidak melaksanakan hipnoterapi sebanyak 11 orang namun setelah melaksanakan hipnoterapi menjadi 18 orang dan juga mengalami penurunan pada skala nyeri berat tidak terkontrol yang tidak melaksanakan hipnoterapi ada 5 orang namun setelah melaksanakan hipnoterapi menjadi tidak ada satu orangpun.

Menurut pengamatan peneliti, saat pemberian hypnoterapi responden dibimbing untuk melakukan imajinasi sehingga mempengaruhi kerja otak,gelombang otak terdiri dari gelombang beta yaitu gelombang otak yang paling umum dan frekuensinya paling tinggi dimana kondisi kerja otak 
dalam keadaan sadar untuk menjaga pikiran tetap terfokus kemudian menjadi gelombang alpha yaitu gelombang otak yang frekuensinya sedikit lebih lambat dibanding beta dimana kondisi kerja otak rileks dan santai, alfa merupakan jembatan penghubung antara pikiran sadar dan bawah sadar, sedangkan theta yaitu gelombang otak yang dihasilkan oleh pikiran bawah sadar dan terjadi pada saat seseorang mengalami keadaan sangat rilaks atau sangat mengantuk, pada kondisi peralihan gelombang otak tersebut akan menghasilkan tubuh

menjadi rileks sehingga dapat melancarkan volume darah dan oksigenasi ke otak dan menghasilkan

hormon endofrin yang dapat menghambat impuls nyeri sehingga

seseorang menjadi rileks. Efek relaksasi hipnoterapi langsung terlihat pada saat responden sedang dalam keadaan kondisi trance yang dalam yaitu responden terlihat santai, tenang dan rileks, bahkan ada beberapa responden tampak tertidur selama terapi hipnosis dan dapat mengikuti sesi terapi sampai selesai dengan penuh konsentrasi. Saat dalam kondisi rileks, perhatian respondenterhadap nyeri teralihkan sehingga persepsi nyeri dan respon terhadap nyeri berubah, nyeri yang dirasakan menurun sampai dengan hilang. Tidak ada efek negatif yang merugikan responden. Hampir semua mengatakan suasana hati menjadi lebih nyaman,tenang dan rileks.

Dismenore pada remaja harus ditangani meskipun hanya dengan

pengobatan sendiri atau non farmakologi, pengobatan sederhana yang dapat dilakukan dengan menggunakan teknik relaksasi dan distraksi seperti pengalihan nyeri dengan menarik nafas panjang, mendengarkan musik, membaca buku ataupun melakukan kegiatan yang disukai. Teknik relaksasi melalui olah nafas merupakan salah satu keadaan yang mampu merangsang tubuh untuk membentuk system penekanan nyeri yang akhirnya menyebabkan penurunan nyeri. Disamping itu juga bermanfaat untuk pengobatan penyakit dari dalam tubuh meningkatkan kemampuan fisik keseimbangan tubuh dan pikiran, karena olah nafas dianggap membuat tubuh menjadi relaks sehingga berdampak kepada keseimbangan tubuh dan pengontrolan tekanan. Pada

teknik relaksasi selain dapat mengurangi intensitas nyeri juga dapat meningkatkan ventilasi paru dan dapat meningkatkan oksigenasi darah (Azizah, 2012).

Salah satu teknik relaksasi nonfarmakologi dan terapi yang dapat

dilakukan di Indonesia adalah Hipnoterapi, karena dengan melakukan teknik hipnoterapi dapat menghasilkan rasa nyaman sehingga rasa nyaman tersebut dapat merangsang hormon endofrin yang dapat menekan rasa nyeri seseorang. Pikiran sadar bisa mengandung semua unsur dari proses yang secara tradisional disebut sebagai "fenomena trans".Kunci dari hypnosis adalah adanya kekuatan sugesti atau keyakinan terhadap sesuatu hal yang positif yang muncul berdasarkan pada konsep dalam pikiran, sehingga akan memberikan energi positif bagi suatu tindakan yang dilakukan. Kajian inti dari hipnosis adalah berpijak pada asumsi dasar bahwa mind control dapat dicoba diterapkan dalam kegiatan intervensi pembedahan jaringan. Hal inilah yang disebut hypnoanesthesia. Keberhasilan menerapkan metode metode hipnoterapi dalam mengurangi bahkan menghilangkan rasa nyeri (hypnoanesthesi), penggunaan metode ini mengakibatkan berkurangnya bahkan menghilangkan rasa nyeri yang di alami tubuh manusia sebagai respon terhadap suatu trauma ataupun adanya intervensi terhadap jaringan. 
Penelitian

Ginandes, membuktikan hipnoterapi juga bisa digunakan untuk meredakan nyeri, melancarkan pernapasan, sertamengatasi gangguan pencernaan.

Dengan hipnoterapi, dapat meningkatkan kadar endorphin dalam tubuh. Endophrin adalah hormonyang dihasilkan tubuh pada saat rileks atau tenang. Hal tersebut dapat digunakan untuk mengurangi rasa nyeri (Setyono, 2011).

\section{F. Simpulan dan saran}

Berdasarkan hasil penelitian dapat disimpulkan bahwa terdapat hubungan antara tingkat nyeri haid dengan hypnoterapi pada remaja putridi SMK Pelita Al-Ikhsan Kecamatan Ujung Jaya Kabupaten Sumedang. Disarankan kepada remaja putri untuk dapat melakukan hypnoterapi dengan baik. Bagi peneliti dapat berkolaborasi dengan guru BP untuk dapat memberikan pemahaman kepada remaja putri

mengenai hypnoterapi sehingga remaja putri dapat melakukan hypnoterapi dengan baik.

\section{G. Referensi}

Kamila,2011.

httprepository.usu.ac.idbitstream 1234 56789316574Chapter\%20II.pdf Diunduhpadatanggal 21 september 2015 pukul 10:00 WIB

Handono, Budi, dkk. 2010. Obstetri fisiologi ilmu kesehatan reproduksi. EGC: Jakarta.

Siahaan Kartika,2013. httpjurnal.unpad.ac.idejournalarticlevi ewFile 709755. Diunduhpadatanggal 21 september 2015 pukul 08:00 WIB

Meli, Dina, 2014. Gambaran

Tingkat Nyeri Haid Pada Remaja Putri Di SMAN Situraja

Kabupaten Sumedang Tahun 2014. Akademi Kebidanan Respati : Sumedang
Lisnawati, Mela. 2013. Hubungan Timbal Balik Antara Tingkat Kecemasan Dengan Kejadian Tingkat Nyeri Haid Di SMAN 3 Sumedang Tahun 2013 Akademi Kebidanan Respati : Sumedang

AstaraYulida Rizqi, 2010. Di httpeprints.ums.ac.id104101J2100600 30.pdf Diunduh pada tanggal 21 september 2015 pukul 10:00 WIB

Handono, Budi. dkk. 2010. Obstetri fisiologi ilmu kesehatan reproduksi.: EGC : Jakarta

Bagus, Ida. 2010. Memahami

kesehatan reproduksi wanita.

Manuaba : Jakarta

Lina,2011.

httprepository.usu.ac.idbitstrea m1234567893165748

Chapter\%20II.pdf Diunduh pada tanggal 21 september 2015 pukul 11:00 WIB

AzizahNoor,2013.

https://www.google.co.id/url?q=http:/ /e-

journal.stikesmuhkudus.ac.id/index.p $\mathrm{hp} /$ karakter/article/download/146/201 3.pdf Diunduh pada tanggal 26 september 2015 pukul 12:30 WIB

Dian,2011.

httprepository.usu.ac.idbitstrea m123456789402304Chapter\%20II.pd f Diunduh pada tanggal 21 september 2015 pukul 13:30 WIB

Jurnal,Anekdot.2014.

http://download.portalgaruda. org/article.php?article $=131357 \& v a l=$ 4108.pdf Diunduh pada tanggal 28 september 2015 pukul 13:50 WIB Andrew, gilly. 2009. Buku ajar kesehatan reproduksi wanita. EGC : Jakarta

Alpha tranceformation institute. 2015. Hypnosis in midwifery. Akademi Kebidanan Respati : Sumedang.

HidayatAlimulAziz. 2014. Metode penelitian kebidanan dan 
teknik analisis data. Salemba Medika : Jakarta

WHO

http://download.portalgaruda.org/artic

le.php?article $=131357 \& \mathrm{val}=4108 . \mathrm{pdf}$

Diunduh pada tanggal 30April 2016 pukul 13:50 WIB

Jurnal.Potter\& Perry(2010)Di

http://download.portalgaruda.org/artic

le.php?article $=131357 \& \mathrm{val}=4108 . \mathrm{pdf}$

Diunduh pada tanggal 30April 2016

pukul 14:50 WIB
Manuaba. 2009. Buku ajar menstruasi. EGC : Bandung

Jurnal.setyono (2011)

http://jurnal.untan.ac.id/index.php/jm

keperawatanFK/article/download/110 37/10505.pdf Diunduh pada tanggal

18 mei 2015 pukul 13:00 WIB 